\title{
A Survey on Rheological Properties of Fruit Jams
}

\author{
Marjan Javanmard and Johari Endan
}

\begin{abstract}
This paper presents the rheology and texture properties in some details to reveal the rheological measurements, and models involved with each detail. Additionally, the methods of color measurements and sensory evaluation were discussed briefly. Some optional methods that have been done in previous literature depicted a proposal for developing innovative techniques for rheological properties of jams. Factors that have an influence on quality of jam consist of color content, taste, flavor, and texture and nutritional value. All the parameters mentioned are affected from the nature of the raw material and the processing conditions. Hence, it is imperative to comprehend the rheological behavior of fruit products such as fruit purees and jams. Especially for pumping and processing where the chemical and physical characteristics can be varied. In this report, novel and important applications of rheology to food gels and gelation phenomena are covered. Furthermore, specialists that work in food should be knowledgeable about sensory assessment of foods therefore food rheologist have reached numerous unique contributions in sensory evaluation of viscosity that will be discussed concisely.
\end{abstract}

Index Terms- Rheology, Fruit Jam, Sensory Characteristics, Hydrocolloid

\section{INTRODUCTION}

Rheology is the study of deformation and flow, being knowledgeable about this physical property of food materials is informative in their processing, handling and storage. During the past few decades the science of fluids and semi fluids rheology has been improved significantly therefore food professionals need to appreciate the fundamental principles and suitable measurements of rheological properties of food as well as the impact of structure and composition on it.

Temperature is one of the most important parameters that influences rheological behavior of food [1]. This fact makes it necessary to be knowledgeable about the relationship between viscosity and temperature.

Fruit and vegetables rheological properties are in interest of food scientists, agriculture engineers, and food engineers, because of several reasons. First of all importance in human diet and secondly the costumer perception of a food product is relevant to its rheological characteristics [1].

The procedure of making fruit jam is a complicated process with a number of variables that affect the quality of the final

Marjan Javanmard and Johari Endan are with the Department of Process and Food Engineering, Faculty of Engineering, University of Putra Malaysia, 43400 UPM, Serdang, Selangor, Malaysia (phone: +60-192376844 e-mail: marjanjavanmard@hotmail.com). product. It is essential to be knowledgeable about the fundamental rheology to enhance the technology of different types of jam. Due to this cause rheology has application in different stages of jam manufacture from process equipment designing to development of products, and quality control.

Fruit jams rheological behavior is influenced by different parameters such as composition which one of most important factors is the fruit type and also the technology of the process. Beside other factors such as shear rate and as mentioned previously temperature.

Fruit and vegetables are either consumed directly or after being processed to products such as fruit purees or jams. Generally, fruit and vegetable purees behave like pseudoplastic fluids [2]. A number of rheological properties of fruit purees have been shown in Table I.

TABLE I. RHEOLOGICAL MODELS OF DIFFERENT FrUIT PUREES

\begin{tabular}{|c|c|c|c|c|c|}
\hline Brix & pH & $\underset{(\mathrm{oC})}{\text { Temp. }}$ & Model & $\begin{array}{l}\text { Fruit } \\
\text { Puree }\end{array}$ & Ref. \\
\hline & $3-5.1$ & $10-55$ & HB & $\begin{array}{c}\text { Banana } \\
\text { Puree }\end{array}$ & [3] \\
\hline & & $20-40$ & $\begin{array}{c}\text { HB, } \\
\text { Ostwald } \\
\text {-Waele }\end{array}$ & $\begin{array}{c}\text { Raspberry } \\
\text { Strawberry } \\
\text { Peach } \\
\text { Prune } \\
\text { Apricot }\end{array}$ & [4] \\
\hline $12-52$ & 3 & $10-55$ & HB & $\begin{array}{l}\text { Peach } \\
\text { Papaya } \\
\text { Mango }\end{array}$ & [5] \\
\hline \multirow[t]{2}{*}{$9.8-16$} & & $25-60$ & $\begin{array}{c}\text { Mizrahi- } \\
\text { Berk }\end{array}$ & Guava & {$[6]$} \\
\hline & & 20 & $\begin{array}{c}\text { Time- } \\
\text { dependent } \\
\text { model of } \\
\text { Weltman }\end{array}$ & Mango pulp & [7] \\
\hline $10-20$ & & $\begin{array}{l}25,40 \\
50,60\end{array}$ & Sisko & $\begin{array}{l}\text { Blueberry } \\
\text { Puree }\end{array}$ & [8] \\
\hline $66-70$ & $\begin{array}{l}3.12- \\
3.30\end{array}$ & & Power Law & $\begin{array}{c}\text { Pistachio } \\
\text { Green } \\
\text { Hull's } \\
\text { Marmalade }\end{array}$ & [9] \\
\hline $\begin{array}{l}16.6 \\
13.3 \\
\end{array}$ & & 30 & $\begin{array}{c}\text { Mizrahi- } \\
\text { Berk }\end{array}$ & $\begin{array}{c}\text { Pineapple } \\
\text { Mango } \\
\text { Pulps }\end{array}$ & [10] \\
\hline
\end{tabular}

Throughout the heating process of fruit purees and jams there is a significant change in there apparent viscosity. This change has an impact on temperature and velocity profiles hence it is necessary to have knowledge regarding to the impact of temperature and shear rate on the rheological behavior of fruit purees [11].This paper reports the rheological behavior of fruit purees and manufactured fruit purees(jams). There are different rheological models that are used to describe the relationship between shear rate and shear stress and the best one will be chosen according to the $\mathrm{R}^{2}$. 
In view of consumer demand for foods with quality, it is critical to characterize food rheological property changes along the processing operation which will influence their overall acceptability.

This paper reports the rheological behavior of jams (manufactured fruit purees) as affected by temperature, shear rate, composition of fruit jams, and type of hydrocolloids, $\mathrm{pH}$ and time. Additionally, rheological measurements and methods will be studied. Eventually, sensory attributes will be discussed.

\section{PRocedure of JAM MANUFACTURE}

In order to produce jams first of all fruit pulps should be pasteurized. The $\mathrm{pH}$ value is controlled with a $\mathrm{pH}$ meter and adjusted in the range of 2.5-3.2, with citric acid. The ingredients of fruit jam are fruit pulp, sugar and glucose syrup, thickeners such as (E-440, E-410), and citric acid to bring the $\mathrm{pH}$ into the desired range. One of the most important facts that have an affect on the rheological behavior of food is there temperature dependence [1].

According to the directive of the European Union Council (2004/84/EC) for definition and labeling of fruit jams, jellies, marmalades, and sweetened chestnut purees for human consummation, pectin gelled formulations of sugar with fruit pulp and/or puree of one or more fruit types and water are termed as jams. Generally, the quantity of fruit required to produce $1000 \mathrm{gr}$ of finished product has to be at least $350 \mathrm{gr}$. The amount of pulp content for manufacture of "extra jam" should not be less than $450 \mathrm{gr}$ per $1000 \mathrm{gr}$ of the finished product. Moreover the soluble dry matter of the product should be determined by refractometer and should not be less that $60 \%$, aside from products that sugar has been completely or partly modified by sweeteners like dietetic products, sugar reduced and sugar free products. Nevertheless some other fruit based products such as spreads have lower sugar and higher amounts of fruit contents and other constitutes like hydrocolloids and preservatives are not standardized in this directive.

Fruit preparations according to the definition given by the German Federation of Food Law and Food Science (BLL) are intermediate products which are used in bakery and confectionary product, dairy products, that in addition to fruit they include diverse sugars, flavors, thickening agents, and food grade acids, and they are preserved with suitable procedures. The fruit content in these kinds of products should not fall under 35\%. Fruit preparations for fruits with high acid or aroma like pineapple or raspberry alike their jams must have lower fruit content, approximately around $25-30 \%$ which is conditional to the variety and species of the fruit that is consumed in the process.

Jams, fruit spread, fruit preparations, and similar fruit products mainly have the same manufacturing process excluding the gelation which is the fundamental difference between them.

Fruit pulp and sugar will be mixed and heated. The total soluble solid should be monitored along the process until the brix reaches $55^{\circ}$. For jam preparation pectin is usually used as pectin solution, this solution is prepared by adding pectin to hot water and heating it until it becomes a homogenous solution. The pectin solution will be added to the fruit pulp and sugar mixture and citric acid is added in this stage, acid is added to bring the $\mathrm{pH}$ in the desired range which is around 3. The mixture should be cooled to temperature around $35^{\circ} \mathrm{c}$ the cooling stage is for the gel formation at it can be done in water bath and then to make sure the gelation is completed it will be stored in room temperature for 24 hours [12].

Jams should be analyzed instantaneously. For determination of proteins and carbohydrates, Kjeldal and Fehling methods are used respectively. Soxhlet method is used for extraction of fats under reflux at $60^{\circ} \mathrm{c}$ for about 8 hours with petroleum ether. A pH meter is utilized to control the $\mathrm{pH}$ level [13].

\section{INFLUENCE OF DIFFERENT PARAMETERS ON PHYSICAL AND SENSORIAL PROPERTIES OF JAMS}

In order to cover the latest developments it is imperative to conclude the following subtitles:

\section{A. Temperature and Viscosity}

One of the most important parameters that have an effect on viscosity is temperature; this effect can be described by (1) where $\Delta \mathrm{E}$ represents the activation energy. If the graph of $\ln \eta$ vs. $1 / \mathrm{T}$ is plotted, the slope would be equal to $\Delta \mathrm{E} / \mathrm{R}$ from (2) we may calculate viscosity at a temperature (T2) derived from values of another temperature (T1).

$$
\begin{aligned}
& \eta=A \exp \left(\frac{\Delta E}{R T}\right) \\
& \ln \eta_{1}-\ln \eta_{2}=\left(\frac{\Delta E}{R}\right)\left(\frac{1}{T_{1}}-\frac{1}{T_{2}}\right)
\end{aligned}
$$

With decrease in the temperature viscosity will increase, from this explanation it can be understood that $\Delta \mathrm{E}$ depends on the model which the viscous flow is described with. Regarding to the free- volume model, configuration of a free volume larger than the volume of a solute molecule is necessitate for flow.

In contrast, in viscous flow the activation energy declares that every molecule of the solvent is enclosed by a sphere of neighbors, which this structure is similar to the preparation of the crystalline solids.

For liquids each molecule of solvent is enclosed by a vacant area, this circumstance that is observed is dissimilar to the solids behavior. When solvent molecules leap into the neighboring empty space flow happens. The encircling neighbors will exchange in every jump.

Concisely, $\Delta \mathrm{E}$ is known as the energy needed to place the molecules in their blank coordination spots [14].

As it has been studied in different type of fruit jams the viscosity will decrease with the increase of temperature moreover time can affect the viscosity as well which will be discussed further.

\section{B. Shear Rate}

Shear rate is described as the velocity gradient in a fluid which is a result of the shear stress that is implemented, it is 
represented by the symbol $\gamma$ and the unit is stated as the reciprocal seconds $(1 / \mathrm{s})$. Shear stress is the force that is applied to the substance tangentially. The rheogram is the plot where shear stress is against shear rates, this is the formal type of rheogarms, however some researcher prefer to plot shear rate against shear stress. In the first shear rate is the independent variable but in the latter shear stress is the independent variable. Using shear stress as an independent variable is frequently required in controlled -stress rheometers [15].

In Newtonian fluids, shear stress and shear rate are directly proportional, so the rheogarm will be a straight line and the graph will begin at the origin. For non-Newtonian fluids their will not be a direct relationship between shear rate and shear stress therefore when the shear rate increases the shear stress will either increase or decrease [16].

In jams which contain gels such as pectin as thickening agent the model is assumed to be non-Newtonian. The models for jam will be discussed further in rheological models.

\section{Composition}

Jams formulation, as any other food product, is a very influential on the products physical properties. This is due to the composition of the matrix that has an impact on the rheology of the produced jam, because of the interactions which take place in the matrix ingredients. Any little alteration in the jam matrix for example replacing part of the sugar with other sweeteners or using different pectin's can create changes in the food matrix constituents as a consequence of changes in the interactions and this phenomena will extremely affect the jams quality $[17,18]$.

For manufacture of traditional jam fruit, sugar, pectin and organic acids such as citric acid are used. In traditional products a high content of soluble solids is desired in order that the products shelf life increases and it can be stored and transported in ambient temperatures. The high content soluble solid is achieved by adding sugar to around $55 \%$. The quality of the raw material and the manufacturing process are the indicators of the final products quality [18]. Typically puree contains around $10 \%$ sugar whilst in fruit jams sugar amount is around $40 \%[19,20]$.

Fruit products that have fiber content or are high in pectin need less pectin in their jam formulation. Fruits with high pectin are usually difficult to handle in process, because of this matter protopectin is extracted. This will lead to changes in the setting behavior, especially if the pectin produced has rapid setting behavior. If the jam includes pulp particles or insoluble fiber they will affect the jam's texture and make it firmer moreover they will decrease jams tendency to syneresis, although they do not participate in the gelling system this affect is due to their water bounding properties [21, 22].

In addition, acidity, total soluble solid substance, and calcium content are all imperative facts influencing pectin gelation [21]

\section{Sugar}

Sugar is used in jams, jellies and marmalades. It is important because it make the shelf life longer, makes the taste better and moreover the texture of the product will be improved these factors make sugar one the most important constituents is fruit processed products. Since the percentage of sugar that is used is usually high choosing a suitable type of sugar is important due to the potential of sugar for recrystallization. Sugars that have high tendency to crystallize like pure dextrose (glucose) are not used, on the contrary refined sucrose is known to be a good sugar for addition to jams because it has low tendency to recrystallization. Sucrose is partly inverted to glucose and fructose in the manufacturing process when the $\mathrm{pH}$ of the product is low. This fact is important because it reduces the tendency of sugar to form crystals [23].

Other parameters that affect jam rheology are time and temperature of the cooking process. To get good sensory attributes there could be a combination of different type of sweeteners, for example sucrose and glucose syrup can be combined since glucose syrup is not so sweet comparing with sucrose consequentially the taste will become fresh and fruity. Another combination that can be used is the mixture of glucose syrup with high-fructose corn syrup (corn syrups are derived from corn, wheat, or other kind of starches by enzymatic hydrolysis or acid which will be contingent upon the process that is applied.) this mixture will give a comparative degree of sweetness as sucrose [24].

\section{E. Citric Acid}

Citric acid is considered necessary to correct the balance which is needed in jam and jelly production. Lime and lemon juice are high in citric acid therefore they can be used as a replacement of citric acid in jam manufacture.

\section{F. Pectin}

The most important application of pectin in food industry and so jams and jellies is as a thickening agent. Frequently, when pectin is added in the formulation the producer is looking for changes in the texture or flow behavior of the final product [24].

It should be noted that pectin is soluble in water but it is insoluble in organic solvents. When adding water to pectin it will give the solution a viscous like behavior.

Pectin can be dispersed in high sugar concentrated syrups when the soluble solids are less than $30 \%$. For rapid solving of pectin the procedure could be done under heating or smooth mixing can be effective. In high sugar concentrations pectin will not dissolve completely [25].

Pectin solution can be prepared with $3-4 \%$ pure pectin but if the amount of pectin increases to around $10 \%$ in hot water the pectin will not be completely dissolved. Degree of esterification is also one of the important facts that have an affect on the solving process; pectins that have low esterification dissolve better. Pectin solutions which are made by high esterified pectin's exhibit slight elastic portions [17].

Generally, manufactured pectin solutions behave like 
pseudoplastic, this behavior is dependent to the raw material and the extraction conditions any alteration in these factors can result in changes of the viscosity[26].Increasing the $\mathrm{pH}$ and ionic strength can decrease the viscosity of the pectin solution.

If low esterified pectin solution is used in mixture with some sugar and calcium salts it will create a soft network that the elastic properties can be measured. Viscous properties of pectin solutions are important in food products especially in fruit based products such as fruit juices, jellies, and fruit jams due to increasing the viscosity which is desired because it gives better mouth feel and a greater sense of fruitiness and also sweetness in the final product.

Manufactured fruit products that are made from low methyl ester pectins reveal pseudoplastic behavior meaning that if the applied mechanical stress increases for instance in pumping process the flow will exhibit a shear thinning behavior. Fruit products that are produced with pectin have considerable yield point and this fact will prevent fruit floating in the process. One technique to avoid floating is to bring the lifting force of the fruit particles lower than the yield point; the adjustment of the yield point can be done by calcium reactivity of the pectin when combined with calcium concentrations and ionic strength. Pectin fruit preparations exhibit slight thixotropic behavior additionally they have the capability to recreate the primary form after the stress is removed.

Jams, jellies and marmalades that include pectin in their formulation are viscoelastic solids. The ratio of the viscosity to the elasticity is dependent to firstly the degree of pectin estrification, secondly the $\mathrm{pH}$ conditions and finally the type of pectin which is used in the process.

Increasing the $\mathrm{pH}$ and decreasing the $\mathrm{DE}$ (dextrose equivalent) of high methyl ester pectin will increase the viscous shear. Comparing the gel made from pectin that is extracted from apple to citrus pectin gels, the apple pectin gel shows high viscous shears whereas citrus pectin gels have more elastic shears and are less viscous. Products that have elastic shear are not so spreadable and exhibit more brittle behavior; moreover they have a higher tendency to syneresis. Figures that are obtained with oscillation technique have revealed that citrus pectin gels have smaller linear viscoelastic region compared with apple pectin gels.

To indicate the portion of elasticity $\left(G^{\prime}\right)$ and viscosity ( $\left.G^{\prime \prime}\right)$ the angle of phase displacement between stress and strain is measured, if the angle is equal to $90^{\circ}$ the material is known to be a pure viscous liquid, if it is equal to $0^{\circ}$ the material is elastic solid and if the angle is in between $0^{\circ}$ and $90^{\circ}$ it would be considered as viscoelastic solid.

Industrial pectin in the market is in two types: i) liquid form in this type pectin is in concentrated form that usually contains around $4 \%$. ii) Powdered dry pectin, this form is a mixture of powder and sugar thus for jelly production only the juice should be added, and it is commonly used in jam and jelly production[27].

\section{G. $p H$ Value}

Acidity of the fruit or its $\mathrm{pH}$ value is one of the most important factors in jam process which should be monitored and controlled. When the fruits used have an inherent high $\mathrm{pH}$ value (low acidity) the $\mathrm{pH}$ is controlled with addition of acid to the formulation. In contrast fruit with low $\mathrm{pH}$ value in other words high acidity are difficult to handle. For instance, if pectin is added to a batch of such fruit the gel will start at once the total soluble solid content has reached to the value desired. In this situation, to increase the $\mathrm{pH}$ value throughout cooking period addition of sodium citrate is appropriate[5].

\section{H. Time}

Flow behavior is either dependent to shear rate, this type is mentioned as time independent or it maybe dependent on both shear rate and also the duration of shear that is applied in this case this behavior is called time dependent [28].

Studies on different types of jams shown that some jams exhibited thixotropic behavior for example in pineapple jam the shear stress depends on shear rate and temperature but in a specific time [29].

\section{RHEOLOGY}

\section{A. Rheological measurements with cone and plate}

Regularly, the geometry employed to measure viscosity of thick solutions and semi-solid substances such as jams is cone and plate. This geometry consists of an inverted cone with a very small degree apex (the degree of the apex is different depending on the type of the cone) which rests on a steel plate. While rotation takes place the cone will form an angle $(\alpha)$ with the steel plate beneath it. The applied stress $(\tau)$ and strain rate for a cone that rotates at an angular velocity $\Omega$ $(\mathrm{rad} / \mathrm{s})$ can be described by:

$\tau=\frac{3 M}{2 \pi R^{3}}$

And

${ }^{*}=\frac{\Omega}{\sigma}$

Where $M$ is torque $(\mathrm{N} / \mathrm{m}), R$ is the radius. The dynamic viscosity $\left(\gamma^{*}\right)$ is the ratio of the stress applied stress to the shear rate.

The cone and plate geometry principle is by variation in the torque whilst the torque changes the velocity is altered.

$\eta^{*}=M K / \Omega$

Where $k=3 . \theta / 2 \pi R^{3}$ is the instrument constant which is dependent to the instrument design.

Fluids such as jams that have viscoelastic behavior make a pressure distribution that is perpendicular to the shear area, this pleasure can be measured [30, 31].

\section{B. Rheological Models}

To select a suitable model to correlate the viscosity to shear rate is dependent to the utilization of an appropriate 
instrument the model parameters. Research illustrated that for exact measurements there should be a laminar flow condition is essential. For fruit jams that contain particles that have non-uniform size at shear rates that are very high or very low it is hard to achieve stability. In turbulent flow that high shear rates are applied breakdown in the structure of products occurs. Generally most jams show non-Newtonian behavior. For this reason, the non-Newtonian models will be discussed in (7, 8 and 9).

The Ostwald de Waelle model or as generally known Power Law model is shown in (6) have been widely used for food processes that include heating and cooling, because it is simply measured with most types of rheological devices and further more in a known shear rate range it gives a good description of the fluid flow behavior. The only drawback is that this model does not give a good fit to data that are obtained when wide shear rates are studied.

$\delta=K \gamma$

(6)

Where $\delta(\mathrm{Pa})$ is shear stress, $K\left(\mathrm{~Pa} \mathrm{~s}^{\mathrm{n}}\right)$ is consistency index, $\gamma\left(\mathrm{s}^{-1}\right)$ is the shear rate and $\mathrm{n}$ which is flow behavior is dimensionless. Most fruit jams revealed breakdown during shearing which indicates shear thinning or pseudoplastic behavior $(0<\mathrm{n}<1)$.

This breakdown in structure is due to hydrodynamic forces which are created throughout shearing [32].

The next model used for food when they have finite yield stress; if this yield stress is included in power law the Herschel-Bulkley (HB) model will be generated:

$\delta=K_{H} \dot{\gamma}^{n_{H}}+\delta_{0}$

Where $\delta(\mathrm{Pa})$ is shear stress, $\delta_{0}(\mathrm{~Pa}), K_{H}$ is consistence index $\left(\mathrm{Pa} s^{n_{H}}\right), \dot{\gamma}\left(\mathrm{s}^{-1}\right)$ is the shear rate and $n_{\mathrm{H}}$ is flow behavior that is dimensionless.

Casson model (8) is the Herschel-Bulkley model with this difference that it will give yield stress when square roots of shear stress $(\delta)$ and shear rate $(\dot{\gamma})$ are plotted against each other on the coordinate axis [33].

$\delta^{0.5}=K_{0 C}+K_{C}(\dot{\gamma})^{0.5}$

The HB model depends on the range of the shear rate [34]. Sisko model which is a three parameter model and relates apparent viscosity to shear rate can be used when high shear rates are applied [34, 35].

$\eta=K_{s} \gamma^{n_{s-1}}+\eta_{\infty}$

Where $\eta \quad$ is viscosity in infinite shear rate, $K_{\mathrm{S}}$ is the consistency coefficient, and flow index behavior $\eta_{\mathrm{s}}$ is for shear thinning fluid (when $\mathrm{n}<1$ ).

The Sisko model is used when high shear rates applied such as in pumping fluid foods and furthermore in mixing process. The Sisko model is known to be a combination of Newtonian and Power Law models. This model can be regarded as a generalized model of Power Law that moreover includes Newtonian substances.

Fruit jams consist from serum that mostly exhibits Newtonian fluids behavior and the particles that have different size and shapes, and the pectin which is the portion in the jam that behaves as the non-Newtonian part. Because jams consist as partly Newtonian and partly non-Newtonian they can be studied with the Sisko model [36].

Other researcher showed that the flow behavior of jams can be acceptably explained by time-independent rheological models, such as the Herschel-Bulkely model for strawberry and apricot jams [37], Casson and Herschel-Bulkley models for strawberry, peach, plum and apricot jam [4], Casson for strawberry and peach jams [38], Power Law model for strawberry jam [39], Power-Law and Herschel-Bulkely models for raspberry, strawberry, peach and prune jam [40].

\section{Modulus of Jelly-like foods}

With knowledge to the theory of rubber elasticity, to determine the stiffness modulus of Jelly-like material, they use the number density $(n)$ of the hypothesis springs or the cross-links that are in the structure. Thermal kinetic energy $\left(\mathrm{k}_{\mathrm{b}} \mathrm{T}\right)$ is accumulated in the springs at ambient temperatures.

$G=n \cdot k_{b} \cdot T\left(\frac{C N_{A}}{m}\right)$

Where $G$ is the shear modulus, $C\left(\mathrm{~g} / \mathrm{cm}^{3}\right)$ is the concentration of the polymer, $\mathrm{m}$ is the springs molecular weight, $N_{\mathrm{A}}$ is the Avogadro's number [14].

\section{SENSORy Characteristics}

\section{A. Sensory evaluation of texture}

To describe liquids terms like viscous, slimy, slippery, smooth and/or sticky are used. Descriptors such as firm, grainy, chewy, brittle, smooth, cohesive, adhesive or fracturable are used for solids. With employing wide range of stress vs. strain that are preformed with instrumental measurements it can be decided that which one matches and what term can be used for the experimented food material.

Those polymer solutions that reveal Newtonian behavior are discerned as slimy. According to Power Law model which states the relationship of stress vs. strain for liquids, the flow index behavior $(n)$ can have different values which present different behaviors. If $\mathrm{n}<1$ is pseudoplastic or shear thinning behavior, $n=1$ it is Newtonian, and if $n>1$ it is dilatant or shear thickening behavior.

Panelists distinguished shear thinning behavior as non slimy

Sliminess $=(n-$ constant $) / m$

Where $\mathrm{n}$ is dependent on the behavior of liquids in different shear stress-strain rates and $\mathrm{m}$ is the proportionality. For material that stick to the wall of containers when poured or in other words have a considerable amount of yield stress $n$ will be equal to 0.5 . 


\section{B. Color}

Color can be defined as one of the most important characteristics of food from consumer's point of view. In food industrial production, preservation and storage often there is a degradation of foods color [41] for instance deterioration of the red color which makes strawberry look freshly and attraction has been a problem in manufacture of this fruit. Color deterioration is generally caused by three factors: i) losing red anthocyanin pigment, ii) configuration of brown pigments, and iii) discoloration due to different causes [42].

One of the most important substances in color quality of fruits either fresh or cooked is the anthocyanins. Anthocyanins are sources of antioxidants, but the downside is that are not suitable throughout processing time. The unsteadiness in color is because of different factors such as temperature, $\mathrm{pH}$, and oxygen and water activity (aw).

Through heating process, discoloration is seen due to polymerization. It has been degraded during the process have had antioxidant capability [43].

Moreover products from maillard reaction have confirmed to have an antiradical agents [44]. All through the heating procedure color and antioxidant capacity can both be affected by degradation of sucrose and color pigments (anthocyanin). Kapjar [45] studied the impact of different type of pectins besides their concentration on the texture and color of raspberry jams and their investigation concluded that both color and texture can be affected by the type of pectins which was used.

Still there is a void on the effect of pectin type on jam color and it has not been studied extensively. Despite the fact that, it has been implied that pectin has a role in color degradation of pectin processed products [46] this effect is not surely know.

In jam production since there is no addition of color or flavor the sensory characteristics such as appearance and taste are dependent on the fruit quality and the kind of fruit used for example fresh fruit, frozen fruit, fruit puree or fruit juice.

In addition the state of ripeness of the fruit can change is important as well for instance over ripe food will lose their structure easily during boiling and are less flavorful. It is good to include that fruit with high water content have less flavor components. Mostly frozen fruit and canned fruit are used in jam manufacture.

\section{CONCLUSION}

To describe the rheological behavior of foods and in the case of this study jam apparent viscosity $\left(\eta_{\text {app }}\right)$ against shear rate $(\gamma \quad)$ is plotted. In comparison apparent viscosity is higher in fruit jams than in fresh fruit puree. Change in apparent viscosity is probably due to sugar presence. Temperature is another parameter that governs the rheological behavior. Fresh or cooked fruit will have different rheological characteristics when temperature is increased. Furthermore increase in temperature results in a decrease of apparent viscosity. In manufacturing products are subjected to shear rates with a wide range therefore it is essential to have knowledge about how viscosity will act within the temperature and shear rate that it is exposed to. This understanding will make the engineers be able to design the most suitable equipment for the operation. After the behavior is analyzed, different models can be employed to determine the rheological parameters. Eventually, a comparison between models will be done to see the most appropriate model of flow behavior in the specific temperature and shear rate. In fruit jams Herschel- Bulkely is usually the best fitting model.

\section{REFERENCES}

[1] M. A. Rao and J.F.Steffe, Viscoelastic properties of foods. London, 1992.

[2] M.A.Rao, "Rheology of liquid foods-A Review " Journal of Textural Studies, pp. 135-168, 1977.

[3] S. N. Guerrero and S. M. Alzamora, "Effect of pH, tempreature and glucose on flow behavior of friou purees: I. Banana puree," Journal of Food Engineering, vol. 33, pp. 239-256, 1997.

[4] E.Carbonell, E.Costell, and L.Duran, "Characterization of flow of Spanish commercial jams," Revista de agroqumica technologia de Alimentos vol. 31, pp. 227-235, 1991.

[5] S.N.Guerrero and S.M.Alzamora, "Effect of $\mathrm{pH}$,tempreature and glucose addition on flow behavior of fruit purees: Peach ,Papaya,and Mango puree," Journal of Food Engineering, vol. 33, pp. 239-256, 1998

[6] A. A. Vitali and M. A. Rao, "Flow behavior of guava puree as a function of temperature and concentration," Journal of Texture Studies, vol. 13, pp. 275 - 289, 1982.

[7] S. Bhattacharya, "Yeid Stress and Time-dependent Rheological Properties of Mango Pulp," Journal of Food Science, vol. 64, pp. 1029-1033, 1999.

[8] C. I. Nindo, J. Tang, J. R. Powers, and P. S. Takhar, "Rheological Properties of Blueberry Puree for Processing Applications," Food Science and Technology, vol. 40, pp. 292-299, 2007.

[9] T. M. Moghaddam, S. M. A. Razavi, F. Malekzadegan, and A. S. Ardekani, "Chemical Composition and Rheological Characterization of Pistachio Green Hull's Marmalade," Journal of Texture Studies, vol. 40, pp. 390-405, 2009.

[10] D. H. Pelegrine, F. C. Silva, and C. A. Gasparetto, "Rheological Behavior of Pineapple and Mango Pulps," LWT, vol. 35, pp. 645-648, 2002.

[11] R.Fugel, R.Carle, and A.Schieber, "Quantity and authenticity control of fruit puree, friut preparation and jams- A Review " Trends in Food Science and Technology, vol. 16, pp. 433-441, 2005.

[12] D. M. Barrett, L. Somogyi, and H.Ramaswamy, Processing Fruits: CRC Press, 2005

[13] W.Horwitz, Official Methods of Analyses,AOAC International, 2002.

[14] R.Owusu-apenten, Introduction to Food Chemistry: CRC Press, 2004.

[15] S. Peryt-Stawiarska and Z. Jaworski, "Fluctuations of the non-Newtonian fluid flow in a Kenics static mixer: An experimental study," Polish Journal of Chemical Technology, vol. 10, pp. 35-37, 2008.

[16] M. A. Rao, Rheology of Fluids and Semi-solid Foods. Gaithersburg: Aspen: publishers, 1999.

[17] K. Holm, K. Wendin, and A. M. Hermansson, "Sweetness and texture perceptions in structured gelatin gels with embedded sugar rich domains," Food Hydrocolloids, vol. 23, pp. 2388-2393, 2009.

[18] C.I.Nindo, J.Tang, J.R.Powers, and P.Singh, "Viscosity of blueberry and raspberry juices for processing applications " Journal of Food Engineering vol. 65, pp. 343-350, 2005.

[19] M.A.Cancela, E.Alvarez, and R. Maceiras, "polymers in Alimentary Industry: Properties of the sodium," Agricultural and Food Chemistry, vol. 2, pp. 1-8, 2003.

[20] M.A.Cancela, E.Alvarez, and R. Maceiras, "Effects of tempreature and concentration on carboxymetheylcellulose with sugar rheology," Journal of Food Engineering, vol. 71, pp. 419-424, 2005.

[21] S.Mizrahi, "A review of physicochemical approach to the analysis of the structural viscosity fluid fruit products "Journal of Texture Studies, vol. 10, pp. 67-82, 1979.

[22] B.Holland, I.D.Unwin, D.H.Buss, McCance, and Widdowson's, The Composition of Foods: fruit and nuts Cambridge, 1992.

[23] M.A.Cancela, E.Ivarez, and R.Maceiras, "Effects of Tempreature and Carboxymethelcellolose with Sugar Rheology," Journal of Food 
Engineering, vol. 71, pp. 419-424, 2005.

[24] H.Endress, F.mattes, and K.Norz, Hnadbook of Food Science Technology, and Engineering vol. 3: CRC Press, 2005.

[25] J. Gigli, C. Garnier, and L. Piazza, "Rheological behaviour of low-methoxyl pectin gels over an extended frequency window," Food Hydrocolloids, vol. 23, pp. 1406--1412, 2009.

[26] Y. H. Yoo, S. Lee, Y. Kim, K. O. Kim, Y. S. Kim, and S. H. Yoo, "Functional characterization of the gels prepared with pectin methylesterase (PME)-treated pectins," International Journal of Biological Macromolecules, vol. 45, pp. 226-230, 2009.

[27] E. Fissore, L. Matkovic, E. Wider, A. Rojas, and L. Gerschenson, "Rheological properties of pectin-enriched products isolated from butternut (Cucurbita moschata Duch ex Poiret)," LWT-Food Science and Technologys, 2009

[28] D.De.Kee, R.K.Code, and G.Turcotte, "Flow properties of time-dependent food stuffs " Journal of Rheology, vol. 27, pp. 581-604, 1983.

[29] Santanu Basu, Shihare, and Raghavan, "Time deoendent rheological characteristics," International Journal of Food Engineering, vol. 3, 2007.

[30] H. A. Barnes, A Handbook of Elementary Rheology vol. 3: Wales, 2000

[31] P.Novotna, A.Landfeld, K. Kyhos, M.Houska, and J.Strohalm, "Use of helical ribbon mixer of measurment of rheological properties of fruit pulps " Czech Journal of Food science, vol. 19, pp. 148-153, 2001.

[32] M.A.Rao, Rheology of Fluids and Semi-solid Foods. Gaithersburg: Aspen: publishers.

[33] G.H.Shah and G.S.Bains, "Flow behavior of peach and apricot pulps and concentrates of some Indian varieties " Journal of Food Science and Technology, vol. 28, pp. 308-311, 1991.

[34] J.F.Steffe, Rheological methods in food process engineering. East Lnasing: Freeman Press, 1996.

[35] S. D. Holdsworth, "Rheological methods used for prediction of the flow properties of the food products :a literature review " Transactions of the institution of chemical engineers, vol. 71, pp. 139-179, 1993.

[36] E.Hernandez, C.S.Chen, J.Johnson, and R.D.Carter, "Viscosity changes in orange juice after ultrafiltration and evaporation," Journal of Food Engineering, vol. 25, pp. 377-386, 1995.

[37] E.Costell, E.Carbonell, and L.Duran, "Chemical composition and rheological behavior of strawberry jams ;relation with fruit content " Acta-Alimentaria, vol. 16, pp. 319-330, 1987

[38] E.Costell, E.Carbonell, and L.Duran, "Rheological indices of fruit content in jams: effect of formulation on flow characteristics on flow plasticity of sheared strawberry and peach jams " Journal of Texture Studies, pp. 375-390, 1993.

[39] N.Grigelmo-Miguel and O. Mart-Belloso, "Influence of fruit dietary fiber addition on physical and sensorial properties of strawberry jams " Journal of Food Engineering, pp. 13-21, 1999.

[40] R. Maceiras, E.Alvarez, and M.A.Cancela, "Rheological properties of fruit purees: Effect of cooking " Journal of Food Engineering, pp. 763-769, 2007.

[41] J.Gimenez, P.Kajda, L.Margomenou, J.R.Piggott, and I.Zabestakis, "A study on the color ans sensory attributes of high- hydrostatic- pressure jams as compared with traditional jams " Journal of the Science of Food and Agriculture vol. 81, 2001.

[42] J.E. Abers and R. E. Wrolstad, "Causative foctors of coloration detioration in strawberry preserves during processing and storage " Journal of Food Science, pp. 78-81, 1979.

[43] P.J. Tsai and H. P. Huang, "Relationship between anthocyanin paterns and antioxidant capacity in mulberry wine during storage " Journal of Food Quality, pp. 497-505, 2004.

[44] C. Manzocco, S. Calligaris, D.Mastrocola, Mc. Nicoli, and CR.Lerici, "Review of non-enzymatic browning and antioxidant capacity in processed foods " Trends in Food Science and Technology, pp. 164-168, 2001

[45] M. Kapjar, V. Pilizota, N.Tiban, D.Subaric, J.Babic, and D.Ackar, "Effect of different pectin addition and its concentration on color and textural properties of raspberry jam," Deutsche LebensmittelRundschau, pp. 164-168, 2007.

[46] C.E. Lewis, J.R.L. Walker, and J. E. Lancaster, "Effect of the polysaccharides on the color of anthocyanins," Journal of Food Chemistry, pp. 315-319, 1995. 